\title{
Measuring the relative efficiency of firms listed on Tehran Stock Exchange
}

\author{
Ehsan Abolfathi*, Mandana Abolfathi and Sadegh Sharifi
}

Young Researchers and Elites Club, Science and Research Branch, Islamic Azad University, Tehran, Iran

\begin{tabular}{|c|c|}
\hline CHRON I C L E & ABSTRACT \\
\hline $\begin{array}{l}\text { Article history: } \\
\text { Received January } 14,2014 \\
\text { Accepted } 10 \text { June } 2014 \\
\text { Available online } \\
\text { June } 18 \text { 2014 } \\
\text { Keywords: } \\
\text { Analysis of Financial Efficiency } \\
\text { DEA } \\
\text { Economic Costs } \\
\text { Accounting Costs }\end{array}$ & $\begin{array}{l}\text { In this study, we provide six complementary models of data envelopment analysis to analyze } \\
\text { the financial efficiency of chosen decision-making units for firms listed on Tehran Stock } \\
\text { Exchange. For this purpose, we consider tapered modeling, the concept of accounting costs and } \\
\text { economic costs and divide the whole process into the two sub-processes in modeling. After the } \\
\text { modeling process, we choose the seventeen companies and thereby, provide a new method for } \\
\text { analyzing the financial efficiency. The proposed method seems to be more appropriate than the } \\
\text { methods proposed in the past and it can deliver better understanding of real-world cases. } \\
\text { Finally, we understand that how this method works for analyzing the financial efficiency of } \\
\text { organizations. }\end{array}$ \\
\hline
\end{tabular}

DEA - Toward Tapered

(C) 2014 Growing Science Ltd. All rights reserved.

\section{Introduction}

During the past few years, there have been many studies on development of data envelopment analysis (DEA) for measuring the relative efficiency of financial firms. In fact, implementation of a DEA model of constant returns to scale has been widely used in issues of financial analysis (Tarawneh, 2006; Bojnec \& Latruffe, 2008; Liu, 2008; Liu et al., 2013). However, applying this model to analyze financial performance is not enough because of two reasons. First, many processes consist of some sub-processes that neglecting these sub-processes and cannot give us a realistic model. Second, the large number of zeroes for DMU is inefficient and large differences in the weights of any information are worrisome. However, in most cases, paying attention to the apparent costs and paying attention to hidden costs as well as apparent costs is more important. Hence, this paper provides six complementary DEA models to analyze the financial efficiency in order to take advantage of models. Estelle et al. (2009) applied the Monte Carlo analysis to compare different DEA models measuring efficiency in the presence of the exogenous variables in a three-stage DEA models for incorporating exogenous inputs. They found that each of these methods had its own advantages depending on situations. Rahimi and Behmanesh (2012) considered 26 active companies in poultry field in order to improve the efficiency and found that the application of neural networks *Corresponding author. E-mail addresses: syahkaly@gmail.com (E. Abolfathi) 
and decision trees for analyzing were more capable than using neural networks alone. Abolfathi (2013) analyzed financial statements of listed companies in Tehran Stock Exchange with a hybrid model of data envelopment analysis (DEA) and artificial neural network (ANN). According to Tsai and Chiou (2009), integrating the ANN and decision tree models provides not only higher rate of prediction accuracy but also important decision rules compared with using the ANN model alone. Sivatha Sindhu et al. (2012) provided a Intrusion Detection System (IDS) for detecting anomalies in networks. The essential part of building lightweight IDS depends on preprocessing of network data, detecting important features and in the design of efficient learning algorithm that classify normal and anomalous patterns. Malinov et al. (2001) developed a model for the analysis and prediction of the

correlation between processing (heat treatment) parameters and mechanical properties in titanium alloys by applying ANN. Hamidi Zadeh et al. (2014) analyzed financial statements of listed companies in Tehran Stock Exchange with a hybrid model of data envelopment analysis (DEA) and ANN technique.

\section{The proposed study}

In DEA model, the relative efficiency of unit $k\left(E_{k}\right)$ is measured as follows,

$E_{k}=\max \sum_{r=1}^{s} u_{r} Y_{r k} / \sum_{i=1}^{m} v_{i} X_{i j}$

subject to

$\sum_{r=1}^{s} u_{r} Y_{r j} / \sum_{i=1}^{m} v_{i} X_{i j} \leq 1, j=1, \cdots, n$

$\sum_{p=1}^{q} w_{p} Z_{p j} / \sum_{i=1}^{m} v_{i} X_{i j} \leq 1, j=1, \cdots, n$

Model (1)

$\sum_{r=1}^{s} u_{r} Y_{r j} / \sum_{p=1}^{q} w_{p} Z_{p j} \leq 1, j=1, \cdots, n$

$u_{r}, v_{i}, w_{p} \geq \varepsilon, r=1, \cdots, s$.

where $Y$ and $X$ represent output and input of different units for different units. Interested readers are referred to Abolfathi (2013) and Hamidi Zadeh et al. (2014). To resolve the problems associated with large differences in weights, we use tapered model from one decision-making unit to another.

$\operatorname{Max} \beta^{T}\left(B y_{0}\right)$

subject to

$a^{T}\left(A x_{0}\right)=1$

$-a^{t}(A X)+\beta^{T}(B Y) \leq 0$

Model (2)

$a \geq 0, \beta \geq 0$

Model (2) can be solved after applying the matrix $\alpha, \beta$ like constant returns to scale model.

\section{Methodology}

Data of the research were extracted from financial statements for selected companies in Tehran Stock Exchange of the first six months of 2013. For selecting companies, first we classified sixty-two companies in terms of return on equity ratio, and then applied DEA constant returns to scale model and remove underperforming units and put the remaining units in the same group. Then again, we used the model of constant returns to scale and remove the units whose efficiencies were less than fifty percent and eventually we have got seventeen firms. We consider the whole process with two sub-processes and inputs of the research DEA model are as follows: administrative costs, general and 
sales $\left(c_{1}\right)$, financial cost $\left(c_{3}\right)$, and amortization expense $\left(c_{2}\right)$. (This cost is not included in the final three models). Outputs of DEA models are operating profit $\left(p_{1}\right)$ and net profit $\left(p_{2}\right)$. Intermediate sizes in the second and the third as well as the fifth and the sixth models which are used, including net sales $\left(i_{1}\right)$ and net other incomes $\left(i_{2}\right)$. The reason for choosing these two as an intermediate measure is that the efficient management of a company is looking to gain more money from the lower cost and more profit from lower income. We have calculated the efficiency of the process with constant returns to scale model and used Lingo software for modeling.

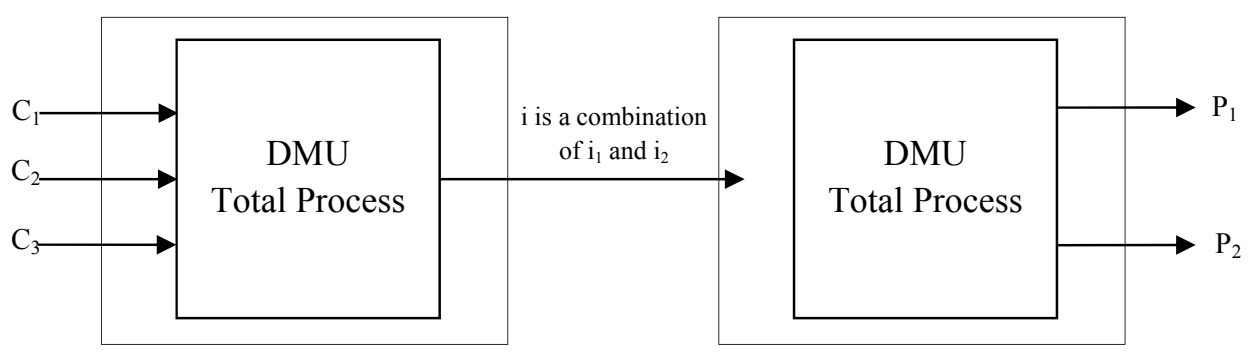

Fig. 1. Related to the second and third models

We provide the fourth model with using model (2) and thus, calculated the total efficiency of the whole process with using the ratio method of tampered. To calculate the matrices $A, B$ in model (2), first from the previous research we consider seven cases as $A, B$ and after trial and error, we chose a case from these seven cases where our goals include reducing the large differences in the weights of one information item to another. Independently for model six, we consider constant returns to scale DEA models for the deployment of the first and second sub-processes and then apply the matrices A, $B_{1}$ constant returns to scale model of first sub-process and applying the matrices $B_{1}$, B to the second sub-process of constant returns to scale. We have created independent tapered hybrid model and solved it with Lingo software. $B_{1}$ matrix has been calculated such as matrices $A, B$, to create the fifth model and named it tapered-communication model. Also, we established tapered model related to two sub-processes with using matrices $A, B, B_{1}$ and multiplied them respectively by inputs, outputs and middle-sized of two sub-processes. In this situation, creating communication model is similar to creating a communication model from the query of constant returns to scale model of the first and second sub-processes. Thus, the fifth model was created by combining tapered and communication model. Now we write the first two models related to the efficiency of the whole and other related efficiency of second sub-process in Lingo software and after calculating whole efficiency and efficiency of second sub-process, we may achieve the efficiency of first sub-process by dividing them. Table 1 is related to the inputs and outputs and intermediate sizes of the first three basic DEA models.

Table 1

Data from the first three models

\begin{tabular}{|c|c|c|c|c|c|c|c|c|}
\hline DMU & Name & $\begin{array}{l}\text { Depreciation } \\
\text { expense }\end{array}$ & $\begin{array}{l}\text { General administrative } \\
\text { and selling expenses }\end{array}$ & $\begin{array}{l}\text { financial } \\
\text { cost }\end{array}$ & $\begin{array}{l}\text { Operating } \\
\text { Profit }\end{array}$ & $\begin{array}{l}\text { Net } \\
\text { Income }\end{array}$ & $\begin{array}{l}\text { Net } \\
\text { sales }\end{array}$ & $\begin{array}{l}\text { Net other } \\
\text { income }\end{array}$ \\
\hline$\overline{\mathrm{DMU}}_{1}$ & Torbatjam sugar & 764 & 1140 & 18080 & 19068 & 19336 & 140902 & 19623 \\
\hline $\mathrm{DMU}_{2}$ & Iran Porcelain Clay & 1235 & 11739 & 58 & 110727 & 94977 & 187102 & 8712 \\
\hline $\mathrm{DMU}_{3}$ & Kharg Petrochemical & 17299 & 1261507 & 0 & 3537766 & 2827501 & 6828246 & 731104 \\
\hline $\mathrm{DMU}_{4}$ & Mobarakeh & 101 & 2903 & 0 & 3586 & 4281 & 30237 & 1591 \\
\hline $\mathrm{DMU}_{5}$ & Lavan Petrochemical & 57405 & 135242 & 0 & 1964832 & 1528469 & 2764910 & 7619 \\
\hline $\mathrm{DMU}_{6}$ & Soliran & 122 & 3725 & 12 & 8080 & 11236 & 30204 & 3470 \\
\hline $\mathrm{DMU}_{7}$ & Tehran drugs & 1231 & 15176 & 1096 & 41045 & 90959 & 242578 & 2193 \\
\hline $\mathrm{DMU}_{8}$ & Urban Baghmisheh & 299 & 31600 & 11458 & 648139 & 642137 & 1047904 & 5456 \\
\hline $\mathrm{DMU}_{9}$ & Petrochemical Fanavaran & 42214 & 610338 & 7236 & 2998326 & 3460226 & 4272081 & 1281937 \\
\hline $\mathrm{DMU}_{10}$ & Mapna & 1156 & 18964 & 1420 & 72614 & 78727 & 397028 & 7523 \\
\hline $\mathrm{DMU}_{11}$ & Pars Khazar & 238 & 6608 & 17319 & 77392 & 131128 & 662496 & 84891 \\
\hline $\mathrm{DMU}_{12}$ & National Development & 356686 & 37418 & 127611 & 1349417 & 1194141 & 1386845 & 0 \\
\hline $\mathrm{DMU}_{13}$ & Tuka Rail & 511 & 19194 & 31456 & 209082 & 156983 & 665237 & 24871 \\
\hline $\mathrm{DMU}_{14}$ & Alborz & 11764 & 26964 & 0 & 128724 & 145126 & 148602 & 23488 \\
\hline $\mathrm{DMU}_{15}$ & Magsal Agri & 1207 & 6592 & 2865 & 67284 & 67677 & 176610 & 3374 \\
\hline $\mathrm{DMU}_{16}$ & Pasargad & 1356 & 12095 & 141025 & 336296 & 197460 & 348391 & 2169 \\
\hline $\mathrm{DMU}_{17}$ & Amir Kabir Steel & 9399 & 15637 & 13610 & 217129 & 156980 & 730611 & 21238 \\
\hline
\end{tabular}


The first model has not used the mid-sized. Table 2 consists of inputs/outputs and intermediate size for three final models but in model four, we have not intermediate size. We put matrices $A, B, B 1$ before Table 2 .

Table 2

Summarizes the data for the fourth, fifth and sixth models

\begin{tabular}{|c|c|c|c|c|c|c|}
\hline DMU & Name & $\mathrm{C}_{1}$ & $\mathrm{C}_{3}$ & $\mathrm{M}$ & $\mathrm{P}_{1}$ & $\mathrm{P}_{2}$ \\
\hline $\mathrm{DMU}_{1}$ & Torbatiam sugar & 5660 & 37300 & 145807.75 & 23902 & 57740 \\
\hline $\mathrm{DMU}_{2}$ & Iran Porcelain Clay & 11753.5 & 11855 & 189280 & 134471.25 & 300681 \\
\hline $\mathrm{DMU}_{3}$ & Kharg Petrochemical & 1261507 & 1261507 & 7011022 & 4244641.25 & 9192768 \\
\hline $\mathrm{DMU}_{4}$ & Mobarakeh & 2903 & 2903 & 30634.75 & 4656.25 & 12148 \\
\hline $\mathrm{DMU}_{5}$ & Lavan Petrochemical & 135242 & 135242 & 2766814.75 & 2346949.25 & 5021770 \\
\hline $\mathrm{DMU}_{6}$ & Soliran & 3728 & 3749 & 31071.5 & 10889 & 30552 \\
\hline $\mathrm{DMU}_{7}$ & Tehran drugs & 15450 & 17368 & 243126.25 & 63784.75 & 222963 \\
\hline $\mathrm{DMU}_{8}$ & Urban Baghmisheh & 34464.5 & 54516 & 1049268 & 808673.25 & 1932413 \\
\hline $\mathrm{DMU}_{9}$ & Petrochemical Fanavaran & 612147 & 624810 & 4592565.25 & 3863382.5 & 9918778 \\
\hline $\mathrm{DMU}_{10}$ & Mapna & 19319 & 21804 & 398908.75 & 92295.75 & 230068 \\
\hline $\mathrm{DMU}_{11}$ & Pars Khazar & 10937.75 & 41246 & 683718.75 & 110174 & 339648 \\
\hline $\mathrm{DMU}_{12}$ & National Development & 69320.75 & 292640 & 1386845 & 1647952.25 & 3737699 \\
\hline $\mathrm{DMU}_{13}$ & Tuka Rail & 27058 & 82106 & 671454.75 & 248327.75 & 523048 \\
\hline $\mathrm{DMU}_{14}$ & Alborz & 26964 & 26964 & 154474 & 165005.5 & 418976 \\
\hline $\mathrm{DMU}_{15}$ & Magsal Agri & 7308.25 & 12322 & 177453.5 & 84203.25 & 202638 \\
\hline $\mathrm{DMU}_{16}$ & Pasargad & 47351.25 & 294145 & 348933.25 & 385661 & 731216 \\
\hline $\mathrm{DMU}_{17}$ & Amir Kabir Steel & 19039.5 & 42857 & 735920.5 & 256374 & 531089 \\
\hline
\end{tabular}

Table 3 and Table 4, respectively, resulting from the resolution of the efficiency from three primary and three final models.

Table 3

Efficiency of all models for applying to the proposed method for three primary models

\begin{tabular}{|c|c|c|c|c|c|c|c|}
\hline DMU & Name & e Model 1 & e Model 2 & $e_{1}$ Model 2 & $\mathrm{e}_{2}$ Model 2 & $e_{1}$ Model 3 & $\mathrm{e}_{2}$ Model 3 \\
\hline $\mathrm{DMU}_{1}$ & Torbatjam sugar & 80.29 & 14.82 & 100 & 14.82 & 100 & 14.82 \\
\hline $\mathrm{DMU}_{2}$ & Iran Porcelain Clay & 100 & 60 & 100 & 60 & 100 & 60.82 \\
\hline $\mathrm{DMU}_{3}$ & Kharg Petrochemical & 100 & 53 & 100 & 53 & 100 & 53.25 \\
\hline $\mathrm{DMU}_{4}$ & Mobarakeh & 54.49 & 15 & 100 & 15.7 & 100 & 15.74 \\
\hline $\mathrm{DMU}_{5}$ & Lavan Petrochemical & 100 & 72 & 100 & 73 & 100 & 73.03 \\
\hline $\mathrm{DMU}_{6}$ & Soliran & 84.5 & 32 & 100 & 39 & 100 & 39.06 \\
\hline $\mathrm{DMU}_{7}$ & Tehran drugs & 59.82 & 32 & 74 & 43 & 76 & 43.22 \\
\hline $\mathrm{DMU}_{8}$ & Urban Baghmisheh & 100 & 70 & 100 & 70 & 100 & 70.85 \\
\hline $\mathrm{DMU}_{9}$ & Petrochemical Fanavaran & 90.93 & 48 & 65.9 & 75 & 100 & 82.94 \\
\hline $\mathrm{DMU}_{10}$ & Mapna & 46.54 & 22 & 100 & 22 & 100 & 22.66 \\
\hline $\mathrm{DMU}_{11}$ & Pars Khazar & 97.5 & 20 & 100 & 20 & 100 & 20.73 \\
\hline $\mathrm{DMU}_{12}$ & National Development & 100 & 36 & 36 & 100 & 36 & 100.00 \\
\hline $\mathrm{DMU}_{13}$ & Tuka Rail & 51.04 & 15.75 & 48 & 32 & 48 & 32.30 \\
\hline $\mathrm{DMU}_{14}$ & Alborz & 47.62 & 30 & 30 & 100 & 100 & 100.00 \\
\hline $\mathrm{DMU}_{15}$ & Magsal Agri & 50 & 33 & 76 & 43 & 76 & 43.79 \\
\hline $\mathrm{DMU}_{16}$ & Pasargad & 100 & 28 & 28 & 99 & 28 & 99.21 \\
\hline $\mathrm{DMU}_{17}$ & Amir Kabir Steel & 64.05 & 29 & 96 & 30 & 96 & 30.54 \\
\hline
\end{tabular}

\section{Table 4}

Efficiency of all models for applying to the proposed method for three final models

\begin{tabular}{|c|c|c|c|c|c|c|c|}
\hline DMU & Name & e Model 4 & e Model 5 & $e_{1}$ Model 5 & $e_{2}$ Model 5 & $e_{1}$ Model 6 & $e_{2}$ Model 6 \\
\hline $\mathrm{DMU}_{1}$ & Torbatjam sugar & 18.19 & 5.76 & 41.4 & 13.9 & 41.21 & 14.64 \\
\hline $\mathrm{DMU}_{2}$ & Iran Porcelain Clay & 68.38 & 46.7 & 78.2 & 59.7 & 78.15 & 59.79 \\
\hline $\mathrm{DMU}_{3}$ & Kharg Petrochemical & 19.63 & 13.8 & 26.5 & 52 & 27.15 & 50.95 \\
\hline $\mathrm{DMU}_{4}$ & Mobarakeh & 11.27 & 23.8 & 51.6 & 46.1 & 51.58 & 14.62 \\
\hline $\mathrm{DMU}_{5}$ & Lavan Petrochemical & 100 & 71.3 & 100 & 71.3 & 100 & 71.38 \\
\hline $\mathrm{DMU}_{6}$ & Soliran & 21.96 & 40.5 & 40.5 & 100 & 40.55 & 36.25 \\
\hline $\mathrm{DMU}_{7}$ & Tehran drugs & 35.05 & 17.1 & 69.5 & 24.6 & 69.66 & 33.81 \\
\hline $\mathrm{DMU}_{8}$ & Urban Baghmisheh & 100 & 65.6 & 100 & 65.6 & 100 & 68.13 \\
\hline $\mathrm{DMU}_{9}$ & Petrochemical Fanavaran & 42.68 & 26.2 & 36 & 72.7 & 36.5 & 79.63 \\
\hline $\mathrm{DMU}_{10}$ & Mapna & 28.82 & 18.1 & 91.4 & 19.8 & 91.1 & 21.29 \\
\hline $\mathrm{DMU}_{11}$ & Pars Khazar & 55.38 & 14.6 & 100 & 14.6 & 100 & 18.32 \\
\hline $\mathrm{DMU}_{12}$ & National Development & 100 & 32 & 32 & 100 & 32 & 100 \\
\hline $\mathrm{DMU}_{13}$ & Tuka Rail & 38.83 & 14.9 & 47.9 & 31.1 & 47.98 & 31.12 \\
\hline $\mathrm{DMU}_{14}$ & Alborz & 41.85 & 25.8 & 28 & 92.1 & 28 & 100 \\
\hline $\mathrm{DMU}_{15}$ & Magsal Agri & 49.45 & 30.7 & 75.9 & 40.4 & 75.95 & 42.23 \\
\hline $\mathrm{DMU}_{16}$ & Pasargad & 34.26 & 10.9 & 11.7 & 93 & 11.79 & 93.01 \\
\hline $\mathrm{DMU}_{17}$ & Amir Kabir Steel & 57.2 & 28.1 & 95.9 & 29.3 & 96.04 & 29.32 \\
\hline
\end{tabular}

In Table 3, as it shown, most companies failed to reach $100 \%$ efficiency in communication model (i.e. the second model) of the second sub-process. 
In addition, companies like sugar Torbatjam, despite having an acceptable efficiency in terms of DEA models in first sub-process, but were not successful in second sub-process. This means that if the company had better efficiency in the second sub-process, it could also achieve higher efficiency in the first model. Other case is about overall efficiency in the first model and overall efficiency in the second model. Their numbers are significantly different from that and it's so important that we describe it in the result. In Table 4, some decision-making units in terms of efficiency compared with the first model for efficiency of tapered models (i.e. the fourth model) are in a better position in terms of ranking. However, some decision-making units are not in terms of this point of view. Pars Khazar is an example of a company that has been in a better position and Soliran is an example of a company that has been in a worse position.

\section{Conclusion and Discussion}

Overall efficiency in a communication model is in fact multiplication of efficiency of the first and second sub-processes. In addition, there is no logical connection between the efficiency of constant returns to scale model of the first model and the efficiency of the communication model in the second model. With calculating the coefficient of determination with rate of 36 percent, there is not a strong correlation between the efficiency of the whole model of constant returns to scale and whole efficiency of communication model. It must be said that each of these performance represents different things. With the first model, we can identify the week companies and with the second model, we can identify weaknesses in the efficiency of first and second sub-processes. Equality answers of the second and third models together for efficiency of first and second sub-processes and equity of solutions of the fifth and sixth models of the same sub-processes indicates that for validation of answers obtained from the second and fifth model, we can use the answer of the third and sixth models and vice versa. Efficiency of second sub-process for the fifth and sixth models are 65.6 and 68.13, respectively. The second reason is that there are larger difference arises from having a great efficiency for one or both sub-processes. Another problem is that the efficiency of second subprocess in the second, third, fifth and sixth models are not suitable for some decision-making units. This is due to their lack of ability to convert the interest to income. Another case is that the overall efficiency in the fourth model (i.e. the tapered model) for decision-making unit from overall efficiency of the first model (i.e. the model of constant returns to scale) is so low. Because the matrix is applied to $\alpha, \beta$ to tapered model is like limitations and limitation make the bad answer for model.

Finally, it must be said that the use of each of these models for the analysis of financial efficiency is like that some people go to the dark room with an elephant in there and each one of them conclude one thing with touching different parts of elephant but the results for detecting the elephant is insufficient. Therefore, by putting together solutions from these models together with the skills and expertise to analyze it, we can have a better understanding of the financial efficiency.

\section{References}

Abolfathi, E. (2013). Analyzing financial statements of listed companies in Tehran Stock Exchange with a hybrid model of data envelopment analysis (DEA) and artificial neural network (ANN). Master Thesis in industrial management, Islamic Azad University, Science and Research Branch, Faculty of Management and Economy, Tehran, Iran

Banker, R. D. (1996). Hypothesis tests using data envelopment analysis. Journal of productivity analysis, 7(2-3), 139-159.

Begum, I. A., Alam, M. J., Buysse, J., Frija, A., \& Van Huylenbroeck, G. (2012). Contract farmer and poultry farm efficiency in Bangladesh: a data envelopment analysis. Applied Economics, 44(28), 3737-3747.

Bojnec, Š., \& Latruffe, L. (2008). Measures of farm business efficiency. Industrial Management \& Data Systems, 108(2), 258-270. 
Estelle, S. M., Johnson, A. L., \& Ruggiero, J. (2010). Three-stage DEA models for incorporating exogenous inputs. Computers \& Operations Research, 37(6), 1087-1090.

Hamidi Zadeh, M.R., Abolfathi, E., \& Abolfathi, M. (2014). Analyzing financial statements of listed companies in Tehran Stock Exchange with a hybrid model of data envelopment analysis (DEA) and artificial neural network (ANN). Indian Journal of Scientific Research, 3(4).

Liu, H. H., Chen, T. Y., Chiu, Y. H., \& Kuo, F. H. (2013). A Comparison of Three-Stage DEA and Artificial Neural Network on the Operational Efficiency of Semi-Conductor Firms in Taiwan. Modern Economy, 4, 20-31.

Liu, P. (2008). DEA Malmquist productivity measure: Taiwanese semi-conductor companies. International Journal of Production Economics, 112, 367-376

Malinov, S., Sha, W., \& McKeown, J. J. (2001). Modelling the correlation between processing parameters and properties in titanium alloys using artificial neural network. Computational Materials Science, 21(3), 375-394.

Rahimi, I., \& Behmanesh, R. (2012). Improve poultry farm efficiency in Iran: using combination neural networks, decision trees, and data envelopment analysis (DEA). International Journal of Applied Operational Research, 2(3), 69-84.

Sivatha Sindhu, S. S., Geetha, S., \& Kannan, A. (2012). Decision tree based light weight intrusion detection using a wrapper approach. Expert Systems with applications, 39(1), 129-141. 1

Tarawneh, M. (2006). A comparison of financial performance in the banking sector: Some evidence from Omani commercial banks. International Research Journal of Finance and Economics, 3, 101112.

Tsai, C. F., \& Chiou, Y. J. (2009). Earnings management prediction: A pilot study of combining neural networks and decision trees. Expert Systems with Applications, 36(3), 7183-7191. 